nik dlya vuzov. [Metal constructions. General course: Textbook for high schools. - 6 th ed]. Moscow: Stroyizdat, 1986. - 560 p.

3. Gorev V.V, Uvarov B.Yu., Filippov V.V, Metallicheskie konstruktsii. Tom 1. EHlementy konstruktsij. [Metal structures. Volume 1. Elements of constructions.] / - 3rd ed. - Moscow: Higher School, 2004. - 528 p.

4. Faibishenko V.K. Metallicheskie konstruktsii: uchebnoe posobie dlya vuzov [Metal structures: a textbook for high schools]. - Moscow: Stroyizdat, 1984. - $336 \mathrm{p}$.

5. SNIP II-23-81*. Stal'nye konstruktsii [Steel structures]. I TSNIISK them. Kucherenko Gosstroy USSR. - Moscow: TSITP Gosstroy of the USSR, 1981. - 163 p.

6. SNIP II-B.3-72. Stal'nye konstruktsii. Normy proektirovaniya [Steel structures. Design standards.] / Gosstroy of the USSR. - Moscow: Stroyizdat, 1974. - $109 \mathrm{p}$.

7. SNIP II-B.3-62. Stal'nye konstruktsii. Normy proektirovaniya [Steel structures. Design standards.] / Gosstroy of the USSR. - Moscow: Stroyizdat, 1969. - $65 \mathrm{p}$.

8. GOST 8509-93. Ugolki stal'nye goryachekatanye ravnopolochnye. Sortament. [Angles steel, hot-rolled, equilateral. Assortment]. - Moscow: Standartinform, 2012. - 12 p.

\section{ИНФОРМАЦИЯ ОБ АВТОРАХ}

Марахина Ольга Юрьевна (Омск, Россия) - студент ПГСб-13П1 ФГБОУ ВО Сибирская государственная автомобильно-дорожная академия (644080, г. Омск, пр. Мupa, 5, e-mail: marahina.olya@mail.ru).

Marakhina Olga Yurievna (Omsk, Russian Federa-tion) -student PGSb-13P1 Siberian state automobile and highway academy (644080, Omsk, pr. Mira, 5, e-mail: marahina.olya @mail. ru).

Кузьмин Дмитрий Андреевич (Омск, Россия) - кандидат технических наук, доцент кафед-ры Cтроительные конструкции ФГБОУ ВО Сибирская государственная автомобильно-дорожная академия (644080, г.Омск, пр. Mupa, 5, e-mail: dimitri_kuzmin@mail.ru).

Kuzmin Dmitriy Andreevich (Omsk, Russian Feder-ation) - candidate of technical Sciences, Associate Professor of Building construction Siberian state automobile and highway academy (644080, Omsk, pr. Mira, 5, e-mail: dimitri_ kuzmin@mail.ru).

\title{
РЕЗУЛЬТАТЫ КОМПЬЮТЕРНОГО МОДЕЛИРОВАНИЯ ТРЕХОСНОГО НАПРЯЖЕННОГО СОСТОЯНИЯ СЖАТОЙ БЕТОННОЙ ПРИЗМЫ УСИЛЕННОЙ МЕТАЛЛИЧЕСКОЙ ОБОЙМОЙ
}

\author{
M.B. Мосин \\ ФГБОУ ВО «СИбАДИ», г. Омск, Россия
}

\begin{abstract}
Аннотация. Проведено компьютерное моделирование в программном комплексе «Лира САПР» и приведены результаты численного моделирования напряженного состояния бетонной призмы обжатой металлической обоймой. Выявлена зависимость между увеличением несущей способности призмы и параметрами конструкции металлической обоймы. Выявлены отличия и сходства напряженно-деформированного состояния сжатых бетонных элементов, обжатых при различных решениях. Предложены основы для разработки методики проектирования металлических обойм.
\end{abstract}

Ключевые слова: Усиление колонн, трехосное сжатие, эфффект обоймы, металлическая обойма, компьютерное моделирование, обжатие колонн, железобетонные колонны, ЛИРА САПР.

\section{ВВЕДЕНИЕ}

В практике строительства и реконструкции объектов часто возникает необходимость уве- личения несущей способности железобетонных колонн [1]. Известен ряд способов усиления колонн, В том числе за счет устройства различных обойм (железобетонных, стальных 
РАЗДЕЛ III.

СТРОИТЕЛЬСТВО И АРХИТЕКТУРА

Таблица 1

РЕЗУЛЬТАТЫ РАСЧЕТОВ НДС БЕТОННОЙ ПРИЗМЫ ОБЖАТОЙ МЕТАЛЛИЧЕСКОЙ ОБОЙМОЙ

\begin{tabular}{|c|c|c|c|c|c|c|c|c|c|c|}
\hline 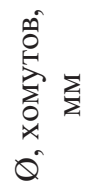 & 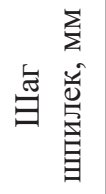 & 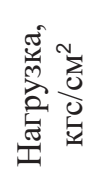 & 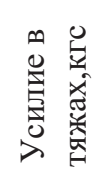 & 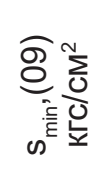 & 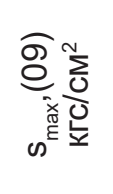 & $\underbrace{\stackrel{0}{*}}_{\omega}$ & $\underbrace{\stackrel{\overbrace{0}^{*}}{*}}_{\omega}$ & $\overbrace{\omega}^{\stackrel{n}{*}}$ & 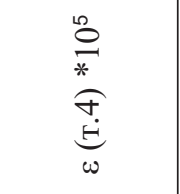 & $\begin{array}{l}\sum_{\Sigma} \\
y \\
y\end{array}$ \\
\hline 0 & & 70 & & 7,315 & 7,315 & 10,520 & 10,520 & 10,520 & 10,520 & $-0,21$ \\
\hline 0 & & 85 & & 8,88 & 8,88 & 15,260 & 15,260 & 15,260 & 15,260 & $-0,305$ \\
\hline 0 & & 100 & & 10,4 & 10,4 & 24,000 & 24,000 & 24,000 & 24,000 & $-0,479$ \\
\hline 0 & & 112 & & 11,7 & 11,7 & 69,800 & 69,800 & 69,800 & 69,800 & $-1,4$ \\
\hline * & & 70 & & $-14,9$ & 3,27 & 0,000 & 9,680 & 0,000 & 9,680 & $-0,204$ \\
\hline * & & 85 & & $-20,2$ & 3,38 & 0,000 & 14,080 & 0,000 & 14,080 & $-0,297$ \\
\hline * & & 100 & & $-27,4$ & 2,73 & 0,000 & 22,200 & 0,000 & 22,200 & $-0,466$ \\
\hline * & & 112 & & $-38,9$ & $-2,82$ & 0,000 & 66,000 & 0,000 & 66,000 & $-1,37$ \\
\hline 0,65 & 50 & 70 & 49,7 & $-4,31$ & 6,33 & 7,945 & 10,295 & 8,067 & 10,296 & $-0,209$ \\
\hline 0,65 & 50 & 85 & 71,9 & $-7,44$ & 7,46 & 11,481 & 14,932 & 11,658 & 14,933 & 0,791 \\
\hline 0,65 & 50 & 100 & 110 & $-13,5$ & 8,25 & 17,895 & 23,442 & 18,172 & 23,445 & $-0,475$ \\
\hline 0,65 & 50 & 110 & 199 & $-24,5$ & 7,58 & 31,665 & 42,234 & 32,161 & 42,248 & $-0,857$ \\
\hline 0,65 & 50 & 115 & 1630 & -53 & $-25,1$ & 255,702 & 1080,450 & 260,464 & 1080,450 & $-21,7$ \\
\hline 0,65 & 50 & 100 & 160 & $-28,2$ & 7,52 & 14,797 & 23,202 & 15,238 & 23,210 & $-0,473$ \\
\hline 0,65 & 50 & 100 & 320 & $-29,1$ & 3,85 & 2,626 & 22,387 & 3,450 & 22,397 & $-0,468$ \\
\hline 1,5 & 50 & 50 & 78,7 & $-6,79$ & 3,6 & 2,306 & 6,002 & 2,493 & 6,003 & $-0,206$ \\
\hline 1,5 & 50 & 70 & 128 & $-11,4$ & 4,7 & 3,741 & 9,960 & 4,047 & 9,961 & $-0,206$ \\
\hline 1,5 & 50 & 100 & 269 & $-23,8$ & 4,94 & 7,865 & 22,719 & 8,511 & 22,726 & $-0,47$ \\
\hline 1,5 & 50 & 110 & 424 & $-33,2$ & 2,63 & 12,388 & 41,060 & 13,409 & 41,082 & $-0,848$ \\
\hline 1,5 & 50 & 115 & 1770 & $-56,4$ & $-28,9$ & 51,842 & 1079,722 & 56,143 & 1079,722 & $-21,6$ \\
\hline 2 & 50 & 100 & 307 & $-25,2$ & 4,12 & 5,01108 & 22,53580 & 5,74696 & 22,54360 & $-0,469$ \\
\hline 3 & 50 & 50 & 106 & $-8,49$ & 3,02 & 0,77672 & 5,88036 & 1,03332 & 5,88068 & $-0,124$ \\
\hline 3 & 50 & 70 & 169 & $-13,7$ & 3,81 & 1,23525 & 9,77062 & 1,64427 & 9,77170 & $-0,205$ \\
\hline 3 & 50 & 100 & 334 & $-26,3$ & 3,5 & 2,43660 & 22,37760 & 3,24778 & 22,38580 & $-0,468$ \\
\hline 3 & 50 & 110 & 489 & $-34,6$ & 1,09 & 3,55002 & 40,62880 & 4,73638 & 40,65260 & $-0,845$ \\
\hline 3 & 50 & 112 & 616 & $-38,8$ & $-2,05$ & 4,46846 & 66,12640 & 5,96410 & 66,16640 & $-1,37$ \\
\hline 0,65 & 100 & 70 & 54,5 & $-3,62$ & 6,96 & 8,67290 & 10,36930 & 9,56894 & 10,41726 & $-0,20934$ \\
\hline 0,65 & 100 & 85 & 79 & $-6,47$ & 8,37 & 12,56194 & 15,03320 & 13,86784 & 15,11596 & $-0,30363$ \\
\hline 0,65 & 100 & 100 & 124 & $-12,1$ & 9,71 & 19,67150 & 23,58520 & 21,73720 & 23,74640 & $-0,47671$ \\
\hline 0,65 & 100 & 110 & 222 & $-22,7$ & 10,2 & 35,24460 & 42,47740 & 39,01920 & 42,81480 & $-0,85915$ \\
\hline 0,65 & 100 & 112 & 357 & $-31,5$ & 9,41 & 56,46840 & 68,67520 & 62,67800 & 69,18700 & $-1,3892$ \\
\hline 0,65 & 150 & 70 & 53,1 & 1,98 & 7,75 & 8,58382 & 10,35432 & 10,42066 & 10,50770 & $-0,20983$ \\
\hline 0,65 & 150 & 85 & 76,8 & 1,22 & 9,52 & 12,43000 & 15,00932 & 15,11768 & 15,24814 & $-0,30436$ \\
\hline 0,65 & 150 & 100 & 120 & $-34,3$ & 10,9 & 19,93364 & 23,59120 & 23,62180 & 23,93800 & $-0,47656$ \\
\hline 0,65 & 150 & 110 & 229 & $-64,5$ & 12,5 & 35,74360 & 42,47980 & 42,54640 & 43,15340 & $-0,87249$ \\
\hline 0,65 & 150 & 112 & 365 & $-92,9$ & 12,6 & 57,43340 & 68,69640 & 68,70120 & 69,73840 & $-1,4696$ \\
\hline
\end{tabular}




\section{РАЗДЕЛ III. СТРОИТЕЛЬСТВО И АРХИТЕКТУРА}

и т.п.). Применение обойм позволяет повысить предельную эксплуатационную нагрузку на колонны за счет: непосредственного включения в работу на восприятие вертикальных нагрузок; снижения поперечных растягивающих деформаций в сечениях усиливаемых колонн; увеличения жесткости и устойчивости колонн. Однако, отсутствует необходимая для проектирования методика по выбору вида обойм и расчету конструктивных элементов усиления. Остается не изучен эфффект включения обойм в работу при отсутствии и наличии предварительного поперечного обжатия [2].

\section{ПРЕДПОСЫЛКИ РАСЧЕТА}

В данной работе выполнена попытка моделирования напряженно-деформированного состояния (НДС) сжатого бетонного элемента усиленного металлической обоймой. В качестве усиливаемого элемента принят бетонный образец в виде прямоугольной призмы. Размеры призмы соответствуют стандартным размерам образцов для испытания на осевое сжатие и равны 100×100x400мм, что позволит в дальнейшем сравнить результаты расчета с экспериментальными данными. В задаче смоделирована металлическая обойма, состоящая из прокатных металлических уголков, устанавливаемых в кромках усиливаемого элемента и стянутых металлическими шпильками. Целью работы является определение зависимости напряженно-деформированного состояния образца от параметров конструкции обоймы: сечения уголка, площади поперечного сечения и шага шпилек. [3]

Расчет модели произведен в программном комплексе «Лира-САПР 2013», реализующей метод конечных элементов в перемещениях. Приложение нагрузки равномерно распределенное по торцевым граням и действует по направлению оси бетонного образца. Нагрузка прикладывалась только к бетонной части модели, без передачи нагрузки на уголки обоймы. В модели предусмотрено отсутствие связи в вертикальном направлении между призмой и элементами обоймы, таким образом обойма воспринимает только горизонтальные усилия распора образца.

Для упрощения расчетной схемы в расчет принята четверть сечения расчетной схемы конструкции с учетом ее двойной симметрии. Узлы, совпадающие с плоскостью симметрии, закреплены от горизонтальных перемещений в направлении, в котором их перемещения должны быть равны нулю.[8]

\section{РЕЗУЛЬТАТЫ РАСЧЕТОВ}

Результаты серии расчетов приведены в табл. 1.

Обойма ограничивает деформации бетона в значительной степени в кромках призмы. Но при этом, за счет перераспределения усилий в материале обжимаемого элемента ограничены деформации бетона вне зоны контакта уголка и образца. Градиент поперечных деформаций боковой грани сжатого элемента с закрепленными от перемещения кромками характеризует угол внутреннего трения материала (наиболее характерное значение для бетона $\left.\varphi=37^{\circ}\right)$. Эфрфект внутреннего трения позволяет перераспределять напряжения от обжатых участков бетонной призмы на смежные к ним. Об угле внутреннего трения можно судить по изополям горизонтальных перемещений испытываемого образца (рис.1).

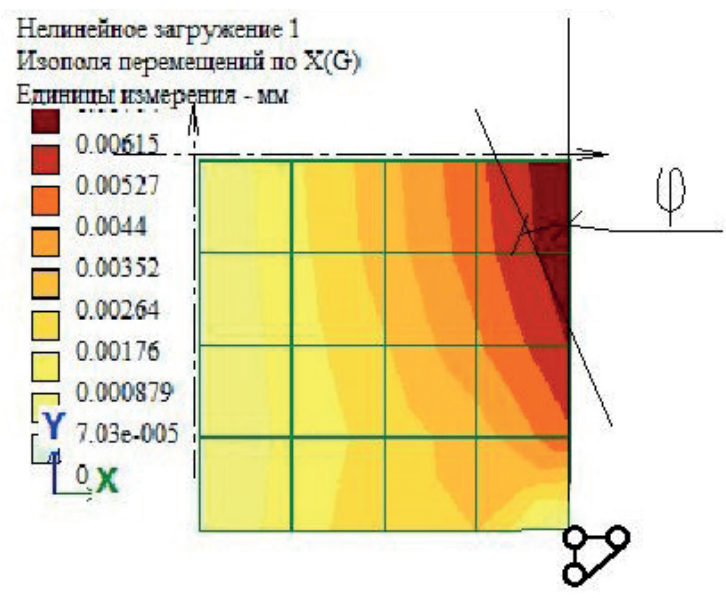

Puc. 1. Изополя горизонтальных деформаций бетонной призмы обжатой в кромке

Максимальные горизонтальные деформации возникают на центральной части боковой грани между шпильками обоймы (тяжами), т.е. на максимальном удалении от точек натяжения уголков обоймы. В той же области развиваются максимальные растягивающие эквивалентные напряжения, что ведет к развитию трещин и разрушению бетона именно на том участке.[7]

При росте сжимающей нагрузки на образец происходят деформации: в продольном направлении - сжатие, а в поперечном - растяжение. Возрастание деформаций вызывает увеличение усилий в тяжах. При линейной постановке задачи зависимость усилий в тяжах от нагрузки линейная, при фризически нелинейной постановке задачи зависимость между 


\section{РАЗДЕЛ III. СТРОИТЕЛЬСТВО И АРХИТЕКТУРА}

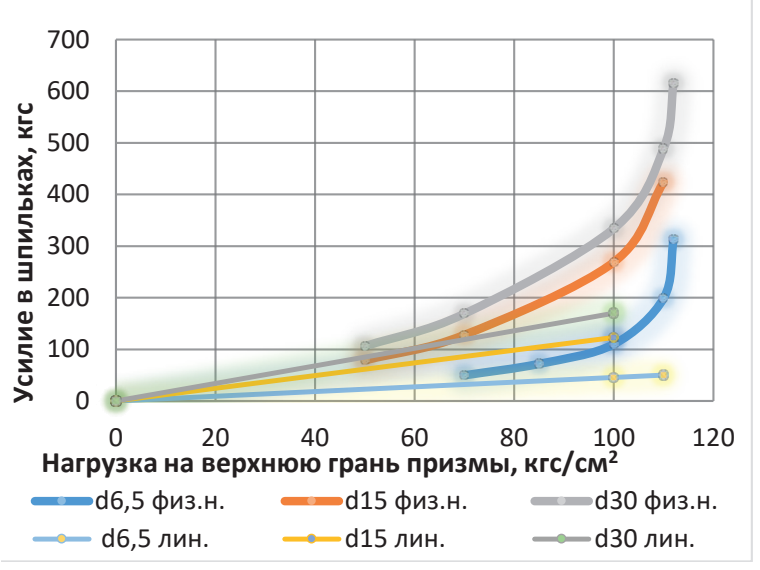

Рис. 2. Диаграмма зависимости усилий, возникающих в шпильках обоймы от сжимающей нагрузки, приложенной к верхней грани призмы

нагрузкой и усилиями в тяжах параболическая с восходящей ветвью (рис.2). То есть усилия в тяжах имеют аналогичную зависимость от нагрузки на усиливаемый образец, как и деформации (в том числе поперечные) в бетоне. Это свидетельствует о прямой зависимости между поперечными деформациями образца и усилиями в тяжах. [4]

На сегодняшний день отсутствует возможность вычислить критическую нагрузку на элемент подверженный трехосному сжатию посредством программных комплексов реализующих метод конечных элементов (Лира, Scad, MicroFE). В ПК Лира за разрушение в конечном элементе (КЭ) принят момент, при котором главные, а не эквивалентные напряжения достигают критического значения растяжения или сжатия при одноосном напряженном состоянии. Таким же образом определяются деформации в КЭ. Деформации в конечных элементах Программным комплексом вычисляются в зависимости от главных напряжений, по закону, определенному при одноосном напряженном состоянии. При этом на основании многочисленных экспериментальных данных выявлено, что прочность и жесткость образцов подверженных трехосному сжатию выше чем у образцов при одноосном сжатии [10]. В данной работе для определения зависимости НДС образца усиленной обоймой от параметров конструкции металлической обоймы в соответствии с предпосылками программы используются результаты расчетов в программе «Лира САПР-2013» при фризически нелинейной постановке. Для приближенного вычисления несущей способности усиленных призм использованы расчеты, основанные на линейной постановке задачи.

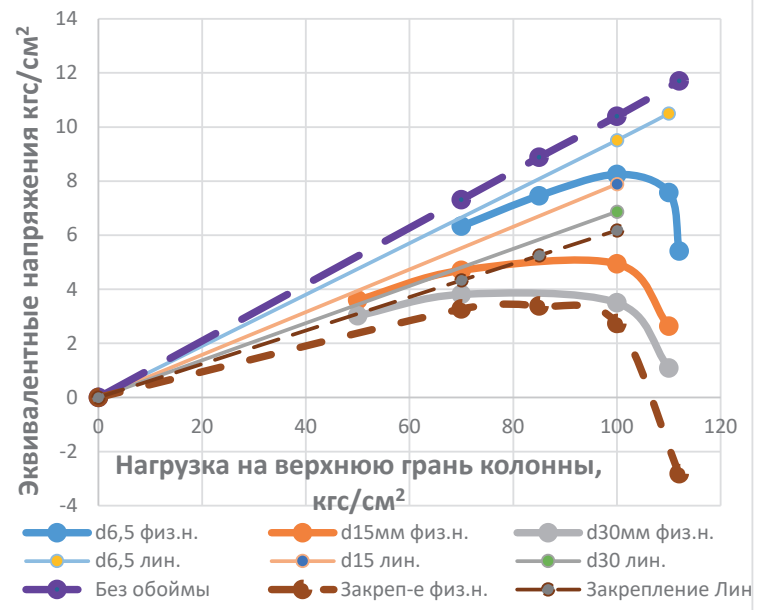

Puc. 3. Эквивалентные напряжения в максимально напряженных конечных элементах в зависимости от нагрузки

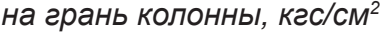

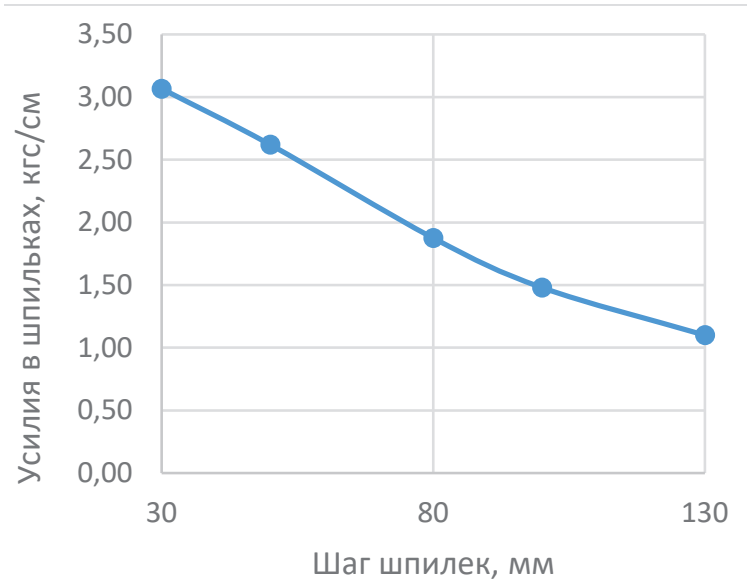

Pис. 4. Усилия, возникающие в шпильках приведенные на единицу высоты конструкции в зависимости от шага шпилек обоймы

Для первого приближения несущей способности при обжатии выполнен расчет при линейной постановке задачи. Таким образом прогнозируемый эффрект усиления составляет $10-70 \%$. Эффрект усиления зависит от параметров обоймы и величины предварительного натяжения шпилек.

Увеличить эфрфект поперечного обжатия можно натянув шпильки динамометрическим ключом до определенного усилия. Усилие в шпильках передается на бетонный образец, вызывая при этом дополнительное обжатие и увеличивая его несущую способность. Метод преднатяжения позволяет полноценно вовлечь обойму в работу при усилении уже нагру- 


\section{РАЗДЕЛ III. СТРОИТЕЛЬСТВО И АРХИТЕКТУРА}

женных элементов, когда поперечные деформации в значительной степени проявлены. Силу натяжения, необходимую для полноценного включения обоймы в совместную работу с бетонной конструкцией можно вычислить исходя из принципа независимости сил. В таком случае сила натяжения шпилек соответствует усилиям, возникающим в них если конструкция нагружена аналогичной нагрузкой, а обойма установлена перед нагружением конструкции.

Наиболее важным параметром металлических обойм при обжатии является шаг шпилек. При уменьшении шага шпилек уменьшается пролет уголка, который в свою очередь работает как многопролетная балка, изгибаемая в двух плоскостях, а так же увеличивается поперечная жесткость обоймы. Уменьшение пролета уголка увеличивает его жесткость, вследствие чего напряжения обжатия по длине кромки бетона передаются более равномерно. Как показатель уровня вовлечения обоймы в работу можно представить усилия в шпильках, приведенные на единицу высоты конструкции. Из диаграммы (рис.4) видно, что зависимость усилий в шпильках на единицу высоты и несущая способность усиленных призм от шага шпилек имеет вид экспоненты. Следует отметить, что при шаге шпилек более 100 мм, соответствующему стороне сечения усиливаемого элемента, прогнозируемая прочность усиленной конструкции ниже неусиленной, что свидетельствует о негативном эфффекте обжатия при неравномерном обжатии кромок призмы. При большом шаге шпилек давление обоймы концентрируется на локальных участках бетонного образца и вызывает завышение эквивалентных напряжений в этой зоне.

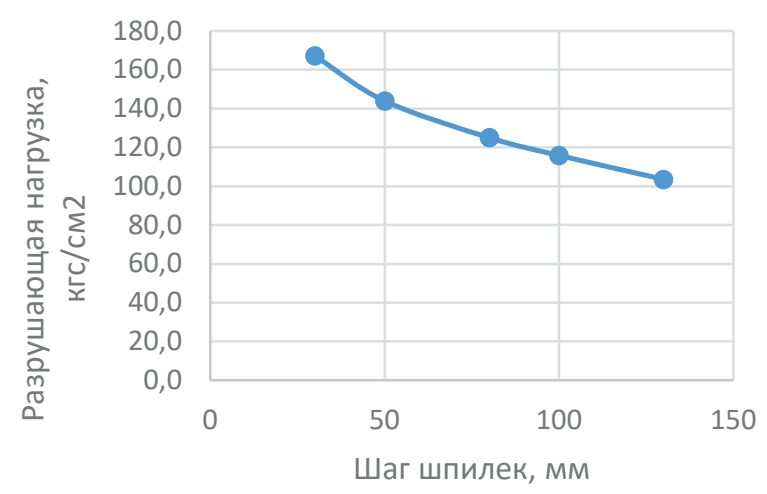

Рис. 5. Несущая способность бетонных образцов обжатых металлической обоймой в зависимости от шага шпилек обоймы

Подбор сечения продольного уголка следует производить исходя из требуемых конструк- тивных размеров и изгибной жесткости. Главным параметром уголка является его изгибная жесткость, чем большую жесткость он имеет, тем равномерней он передает давление обжатия обоймы на усиливаемую конструкцию.

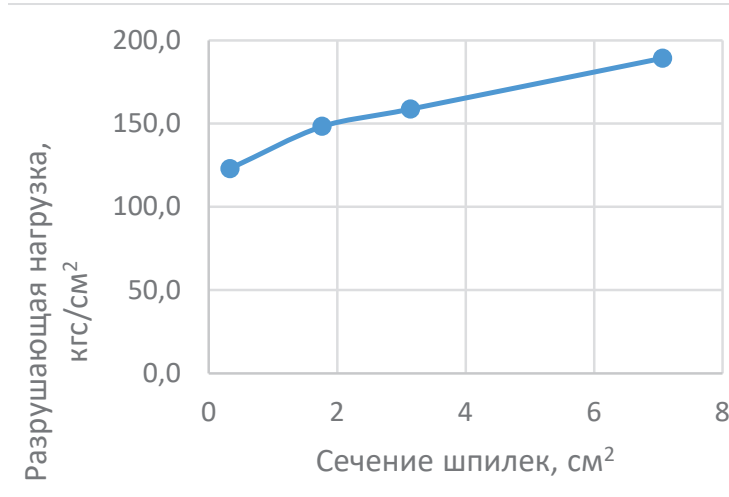

Puc. 6. Графрик зависимости несущей способности бетонных элементов при обжатием от сечения шпилек обоймы

Для определения требуемого сечения уголка вычислим нагрузку, которая на него воздействует. На уголок действует равномерно распределенная по длине нагрузка, равнодействующая которой равна максимальному усилию в тяжах. Из данного условия определим значение равномерно распределенной нагрузки ():

$$
q^{\mathrm{yг}}=\frac{\sqrt{2}}{2} \cdot \frac{R_{s} \cdot A_{\mathrm{HT}}}{h},
$$

где - прочность шпильки на растяжение;

- площадь поперечного сечения шпильки;

- шаг шпилек.

Отсюда определяем требуемый момент сопротивления:

$$
W_{\text {тp }}^{\mathrm{yr}}=\frac{q \cdot h^{2}}{16 \cdot R_{y}} .
$$

Увеличение несущей способности обжатых образцов пропорциональна увеличению площади сечения тяжей обоймы. Данная зависимость связана с увеличением жесткости тяжей (EA). Обойма большей жесткости воспринимает большие поперечные усилия от бетонного образца, следовательно, образец усиленный подобной обоймой имеет бо́льшую несущую способность. Зависимость усилий, возникающих в шпильках обоймы от площади их поперечного сечения отображена на диаграмме на рис. 7. 


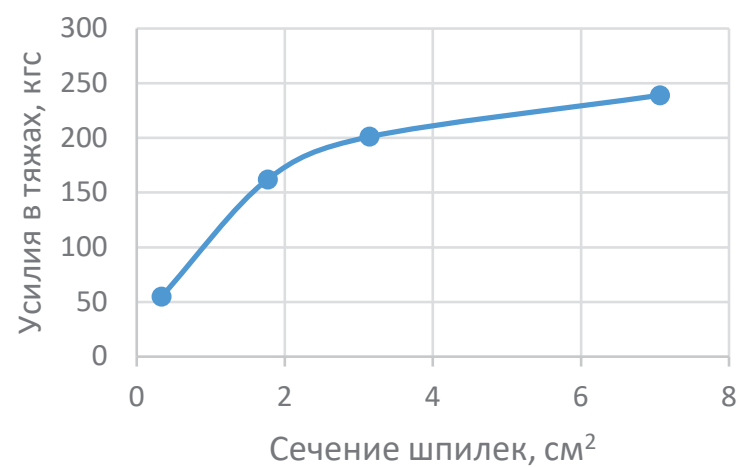

Puc. 7. Графрик зависимости усилий возникающих в шпильках обоймы при усилении бетонных элементов обжатием от сечения шпилек

Поперечная жесткость обоймы, характеризует способность обоймы сдерживать поперечные деформации усиливаемого образца. Значение для металлических обойм выражается в жесткости шпилек приведенная на единицу высоты обжимаемого элемента.

Для металлической обоймы поперечная жесткость вычисляется по фрормуле

$$
\mathrm{D}_{\mathrm{x}}=\frac{\mathrm{EA}}{\mathrm{h}}
$$

где E- модуль упругости шпилек;

А- площадь поперечного сечения шпилек (нетто);

h - шаг шпилек.

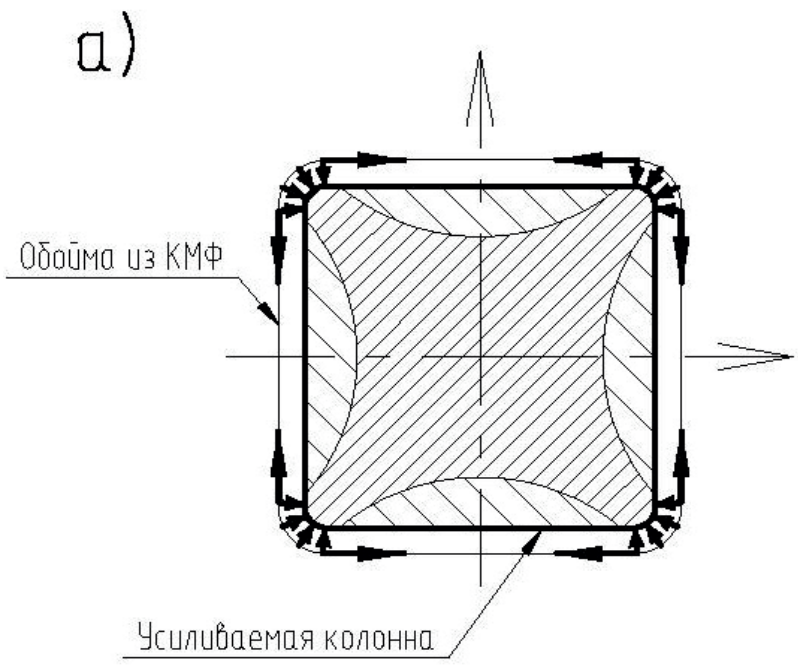

Для сравнения для сплошных обойм из композитных лент

$$
\mathrm{D}_{\mathrm{x}}=\mathrm{E} \cdot t_{f}
$$

где-суммарная толщина слоёв углеволоконной ленты.

Проведем сравнение поперечных жесткостей металлической обоймы и обоймы из углеволокна. Для сравнения рассчитаем поперечную жесткость обоймы из реального проекта из композиционного материала на основе углеродных волокон - MbraceFib CF 230/4900.530g с суммарной толщиной $t f=0,293$ мм. Согласно СП [9] после усиления такой обоймой несущая способность железобетонная колонны из бетона класса В12,5 соответствует классу В30. [5]

$$
\begin{gathered}
\mathrm{D}_{\mathrm{x}}=\mathrm{E} t_{f}=2,04 \cdot 10^{6} \kappa г \mathrm{c} / \mathrm{cm}^{2} \cdot 0,0293 \mathrm{~cm}= \\
=6 \cdot 10^{4} \mathrm{\kappa гc} / \mathrm{cм} .
\end{gathered}
$$

Металлическая обойма с шпильками шагом 20см и диаметром d24мм $\left(A=4,52 \mathrm{~cm}^{2}\right)$.

$$
\begin{aligned}
D_{\mathrm{x}}=\frac{\mathrm{EA}}{\mathrm{h}}= & \frac{2,06 \cdot 10^{6} \mathrm{\kappa г \textrm {c }} / \mathrm{cm}^{2} \cdot 4,52 \mathrm{~cm}^{2}}{20 \mathrm{cM}}= \\
& =4,7 \cdot 10^{5} \mathrm{\kappa г \textrm {c }} / \mathrm{cm} .
\end{aligned}
$$

Таким образом погонная жесткость металлической обоймы в 8 раз выше обоймы из КМФ, благодаря чему может быть более эф-

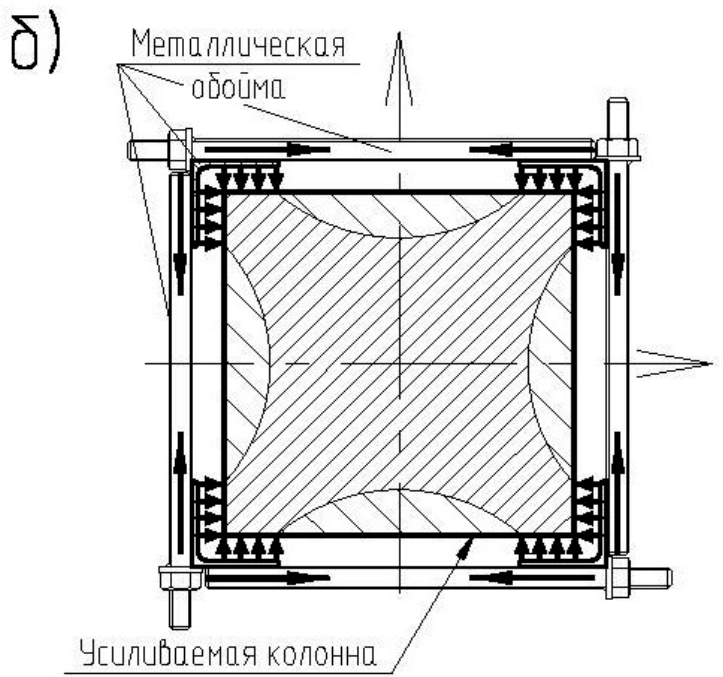

Puc. 8. Схема напряженного состояния системы бетонный элемент-обойма: а) при усилении обоймой из композитного материала б) при усилении металлической обоймой 
фрективно включена в работу. Однако, стоит отметить что из-за специфики конструкции металлической уголковой обоймы ее жесткость не равномерна по высоте конструкции, следовательно, положительный эфрфект может быть снижен.

Напряженное состояние прямоугольных колонн усиленных металлической обоймой соответствует НДС колонн аналогичного сечения, усиленных обоймой из углеволокна. Это явление можно объяснить тем, что обоймы из углеволокна обжимают только лишь кромки элемента подобно металлической уголковой обойме. Действие обоймы проиллюстрировано на рис. 8.

\section{выводы}

Таким образом для теоретического описания прочности элемента усиленного металлической обоймой, можно использовать теоретические описания, используемые для расчетов усиления элементов, обжатых холстами из композитных материалов. Тем не менее существуют отличии, изменяющие эффект усиления как в положительную, так и в отрицательную сторону.

- При обжатии металлической обоймой давление уголка по длине кромки усиливаемого элемента имеет переменное значение. В уровне шпилек уголок передает бо́льшее значение обжатия, чем в уровне между шпильками. В элементе, усиленном обоймой из КМФ, теоретически обжимные напряжения распределены равномерно по длине кромки.

- Металлическая обойма обладает бо́льшей жесткостью чем обойма из КМФ. Более высокая жесткость обоймы позволяет более качественно сдерживать поперечные деформации бетона. Оценка жесткости обойм приведена выше.

- При помощи металлической обоймы за счет использования шпилек можно достигать более высоких значений обжатия чем при использовании обоймы из композитов.

- Металлическая обойма имеет бо́льшую площадь контакта с усиливаемым элементом в отличие от обоймы из КМФ, что увеличивает активную площадь обжатия. [6]

- Возможность комбинированного использования металлической обоймы при обжатии и включение уголка в работу на восприятие продольных усилий.

\section{БИБЛИОГРАФИЧЕСКИЙ СПИСОК}

1. Карпенко, Н.И. Общие модели механики железобетона / Н.И. Карпенко. - Москва: Стройиздат, 1996. -416с.

2. Оценка эффрективности различных методов усиления железобетонных колонн / М. В. Мосин [и др.] // Архитектура, Строительство, Транспорт материалы Международной научно-практической конференции. 2-3 дек. 2015 г. / СибАДИ. - Омск, 2015. С. 363-367.

3. Мосин, М. В. Компьютерное моделирование трехосного напряженного состояния сжатой бетонной призмы / Мосин, М.В.[и др.] // Техника и технологии строительства. №4 (8). C. 91-97.

4. Берг, О.Я. Физические основы теории прочности бетона и железобетона/ О.Я. Берг.Москва: Госстройиздат, 1962. -96с.

5. Шилин, А. А. Внешнее армирование железобетонных конструкций композитными материалами./ А. А. Шилин [и др.] - Москва: Стройиздат, 2007. -184c.

6. Tarabia, A. M., Albakry H. F. Strengthening of RC columns by steel angles and strips // Alexandria Engineering Journal. September 2014. стр. 615-626.

7. Римшин, В. И., Усиление железобетонных конструкций обоймами из композиционных материалов / В. И. Римшин, Ю. О. Кустикова // Строительная физика в XXI веке. - Москва. 2006. - С. 542-545.

8. Мурашов, В. В. Дефекты монолитных деталей и многослойных конструкций из полимерных композиционных материалов и методы их выявления [Текст].Ч. 1. Дефекты монолитных деталей и многослойных конструкций из полимерных 161 композиционных материалов / В. В. Мурашов, А. Ф. Румянцев // Контроль. Диагностика. - 2007. - № 4. - С. 23-31.

9. Свод правил по проектированию и строительству: Усиление железобетонных конструкций композитными материалами. Правила проектирования [Текст]: СП 164.1325800.2014 : введ. 01.09.2014. - М.: Минстрой России, 2015. - 56 с.

10. Морозова, Т. С. Внешнее армирование железобетонных колонн композиционным материалом на основе углеволокон [Текст] / Т.С. Морозова, В. Д. Кузнецов //Инженерно-строительный журнал. - 2010. - №3. - С. 35-38. 


\title{
RESULTS OF COMPUTER SIMULATION TRIAXIAL STATE OF STRESS PRISM COMPRESSED CONCRETE REINFORCED WITH METAL CLIP
}

\begin{abstract}
Computer modeling in the software package "Lira SAPR" and the results of numerical modeling of the stress state of the concrete prism crimped me-metallic clip. The dependence between the increase in carrying capacity of prize-we design parameters of the metal holder. Revealed differences and similarities for example-mately-deformed condition compressed concrete elements crimped at different re-sheniyah. Proposed a framework for the development of a technique of designing of metal clips.
\end{abstract}

Keywords: Reinforcement of columns, triaxial, the effect of the cage, metal cage, computer simulation, compression columns, concrete columns, LIRA SAPR.

\section{REFERENCES}

1. Karpenko N.I. Obshchie modeli mekhaniki zhelezobetona. [General mechanics model of reinforced concrete]. Moscow, Strojizdat, 1996. $416 \mathrm{p}$.

2. Mosin M. V., Ivasyuk I. M., Tishkov E. V., Bolinger YU. YU. Ocenka ehffektivnosti razlichnyh metodov usileniya zhelezobetonnyh kolonn. [Evaluating the effectiveness of various methods of strengthening concrete columns]. Materialy Mezhdunarodnoj nauchno-prakticheskoj konferencii «Arhitektura, Stroitel'stvo, Transport» [Materials of the International scientific and practical conference «Architecture, Construction, Transport»]. Omsk, 2015, pp. 363-367.

3. Mosin M. V., Aleksandrov A. A., Ivasyuk I. M., Tishkov E. V. Komp'yuternoe modelirovanie trekhosnogo napryazhennogo sostoyaniya szhatoj betonnoj prizmy [Computer simulation of a triaxial stress state of the compressed concrete prisms]. Equipment and technologies of construction, no 4 (8), 2016, pp. 91-97.

4. Berg O.YA. Fizicheskie osnovy teorii prochnosti betona i zhelezobetona [Physical bases of the theory of durability of concrete and reinforced concrete]. Moskva: Gosstrojizdat, 1962. $96 \mathrm{p}$.

5. SHilin A. A. Vneshnee armirovanie zhelezobetonnyh konstrukcij kompozitnymi materialami. [External reinforcement of concrete structures with composite materials]. Moscow, Strojizdat, 2007. pp 90-110.

6. Tarabia A. M., Albakry H. F. Strengthening of RC columns by steel angles and strips. Alexandria Engineering Journal. September 2014. pp. 615-626.

7. Rimshin V. I., Kustikova YU. O. Usilenie zhelezobetonnyh konstrukcij obojmami iz kompozicionnyh materialov [Strengthening of rein- forced concrete structures collars made of composite materials]. Construction physics in the $21 \mathrm{st}$ century, Moscow, 2006. pp. 542-545.

8. Murashov, V. V. Defekty monolitnyh detalej i mnogoslojnyh konstrukcij iz polimernyh kompozicionnyh materialov i metody ih vyyavleniya [Defects of Monolithic Details and Laminated Structures Made of Polymer Composite Materials and Methods of Detecting Them. Part.1 Defects of Monolithic Details and Laminated Structures Made of Polymer Composite Materials]. Testing. Diagnostics, 207, no. 4, pp. 23-31.

9. SP 164.1325800.2014. Svod pravil po proektirovaniyu i stroitel'stvu: Usilenie zhelezobetonnyh konstrukcij kompozitnymi materialami. Pravila proektirovaniya [Strengthening of reinforced concrete structures by FRP composites Regulation of design]. Moscow, Minstroj Rossii, 2015, 56 p.

10. Morozova, T. S., Kuznecov V. D. Vneshnee armirovanie zhelezobetonnyh kolonn kompozicionnym materialom na osnove uglevolokon [External reinforcing of reinforced concrete columns composite material on the basis of carbon fibers]. Construction magazine, 2010, no.№3, pp. 35-38.

\section{ИНФОРМАЦИЯ ОБ АВТОРЕ}

Мосин Максим Владимирович (Омск, Россия) - аспирант кафредры «Строительные конструкции» ФГБОУ ВО «СИбАДИ» (644080, 2. Омск, пр. Мupa,5; e-mail: maksim.mosin@ mail.ru).

Mosin Maxim Vladimirovich post graduate student of the Building structures Department of the Siberian State Automobile and Highway Academy (644080, Omsk, Mira ave., 5, e-mail: maksim.mosin@mail.ru). 